\title{
La proyección social: una estrategia para la formación integral en el programa de Bacteriología de la Universidad de Córdoba- Colombia
}

\author{
Agustina María Noble González Esp. ${ }^{1}$, Nydia Nina Valencia Jiménez \\ MSc. ${ }^{2}$, Jorge Eliecer Ortega Montes Mag. ${ }^{3}$
}

\author{
${ }^{1}$ Docente Facultad de Ciencias de la Salud de la Universidad de Córdoba. \\ Programa de Bacteriología; ${ }^{2}$ Desarrollista Familiar, Docente de Trabajo Comunitario \\ de la Facultad de Ciencias de la Salud de la Universidad de Córdoba. Programa de Bacteriología, \\ ${ }^{3}$ Coordinador Comité de Acreditación y Currículo \\ del Programa de Ciencias Sociales. Director Grupo de Investigación Desarrollo, Democracia \\ y Planeación Local Regional. Docente de la Facultad de Educación y Ciencias Humanas \\ de la Universidad de Córdoba. Programa de Ciencias Sociales.
}

Correspondencia: nivaji@hotmail.com

Recibido: 02/08/2012 Aceptado: 07/12/2012

\section{Resumen}

El presente artículo se fundamenta en el principio que concibe la proyección social como una estrategia válida en la formación integral de los estudiantes de bacteriología. Es una apuesta que implica repensar el carácter socio humanístico de los currículos de bacteriología y la responsabilidad social de las universidades, desde un enfoque neo institucionalista sociológico que convoca al restablecimiento de la confianza, la potenciación de las redes de cooperación, la visibilización de las comunidades y la sociedad civil en la toma de decisiones curriculares. A la luz de estos argumentos, se presentan las reflexiones y vivencias de un grupo de docentes y estudiantes de la Universidad de Córdoba, que sin pretender dar respuestas a todos los desafíos que enfrentan los programas de bacteriología al momento de construir sus derroteros académicos, es un aporte hacia la toma de conciencia colectiva frente a la importancia de incorporar proyectos y acciones tendientes a resignificar el concepto de formación integral desde la triada docencia- proyección social- investigación.

Palabras clave: Bacteriología, responsabilidad social, educación

The social outreach: a strategy for well-rounded education in he Bacteriology Program at University of Cordoba (Colombia)

\begin{abstract}
This article is based on the principle that social projection is a valid strategy for the comprehensive education of bacteriology students. This proposal consists in rethinking the bacteriology socio humanistic
\end{abstract}


curriculum as well as the universities social responsibility from a neo-institutional sociological approach to reestablishing the trust, improving networks cooperation, community visibility and civil society in curricular decision-making process. . In the view of these arguments are presented thoughts and experiences from a group of teachers and students of the University of Cordoba without pretending to find answers to all the challenges that bacteriology programs face when building their academic paths. This is a contribution to the collective awareness of the importance of incorporating projects and actions to re-evaluate the concept of comprehensive training from the triad-teaching-research-social outreach.

Key Words: Bacteriology, social responsibility, education.

\section{Introducción}

\section{Referentes de la proyección social en el ámbito educativo}

Formar integralmente se ha constituido, en las últimas décadas, en el eje fundamental de la Educación Superior. Convirtiéndose en uno de los principios que garantizan el cumplimiento de la misión y visión que persiguen las Instituciones educativas por todo el mundo. En parte, porque se ha venido reconociendo que el desarrollo de una región no está determinado sólo por las funciones que han de realizar las instituciones, como lo planteaban los teóricos del viejo institucionalismo, sino que también es el reflejo de una gama de costumbres, representaciones y conductas individuales de los miembros de dicha sociedad.

En este contexto, formar integralmente es reconocer, desde las instituciones educativas, que existe un compromiso hacia la construcción de una sociedad más ecuánime, justa y humana, que brinde a todos los hombres y mujeres oportunidades y opciones para vivir una vida que desean y aspiran tener. De allí, que el reconocimiento social de una institución en particular sólo se obtiene cuando ésta demuestra estar comprometida con la solución de las necesidades de la colectividad, transmitiendo su esencia y constituyéndose en la respuesta a los retos y desafíos de formación esperados (1).

Las Instituciones de educación superior vienen articulándose a estas tendencias, no de la forma como la sociedad espera y necesita, sino de la manera como sus propias dinámicas se lo permiten. En este sentido Harvey y Marret (2) afirman que mientras la sociedad demanda velozmente la explicación y comprensión de sus problemáticas, las instituciones académicas responden lento a estos desafíos. Debido, quizás, a su naturaleza contemplativa de los fenómenos sociales. No obstante, es indiscutible que los aportes que éstas realizan son fundamentales en la construcción de nuevos conocimientos que perfilen los derroteros de las políticas públicas en pro del desarrollo humano.

De hecho, el discurso de que las instituciones de educación superior deben establecer un compromiso con la realidad social, no es un tema nuevo, se encuentra "ad portas" de cumplir un centenario. No se debe olvidar, que fue en 1918 cuando incursionó en el ámbito educativo el concepto de extensión universitaria, como una de las bases programáticas que estableció la llamada Reforma Universitaria liderada por los estudiantes argentinos de la Universidad Nacional de Córdoba (3), que proclamaron romper las cadenas del régimen anacrónico por una universidad democrática, en la que el conocimiento fundamentara el desarrollo del pueblo y no se quedara enclaustrado al servicio de unos pocos.

Estos cimientos ofrecieron una nueva mirada latinoamericana a las funciones sustantivas de las instituciones de educación superior. Indudablemente se 
hacía necesario adoptar una perspectiva de cambio institucional, que siguiendo a North (4), se registra de forma incremental respondiendo a cambios culturales y a la información y formas de procesamiento de los planificadores de las políticas, cuya visión ideológica fomentará u obstaculizará las transformaciones esperadas.

Razones que podrían explicar la falta de interacción entre la academia, la investigación y la proyección social, que se evidenció en el siglo pasado y que aún es tendencia en la mayoría de las instituciones educativas, dado que los requerimientos de los estudiantes no se encuentran en correlación con la filosofía de las estructuras académicas administrativas de las instituciones. Los esfuerzos por articular las funciones sustantivas de las universidades sólo se vieron evidenciadas, con el transcurrir de los años, en la conformación de unidades desarticuladas a las políticas institucionales que en procura de responder a estas nuevas demandas empezaron a ofrecer propuestas culturales, deportivas y recreativas como intentos aislados de responder a la formación integral, con poco o nulo impacto en el ámbito social.

Sin embargo, como lo plantea Castillo (5), los cambios en las universidades no obedecen a una sola causa. Las transformaciones en materia de educación superior convocan diversos factores que van emergiendo en determinados momentos de la vida universitaria. En esta dirección, el sentir y querer de la comunidad universitaria no es suficiente para demandar la formulación e implementación de nuevas políticas, se requiere de la fuerza del macro contexto donde se halla inmersa. En este caso, la definición de lineamientos enmarcados en la política pública educativa podría suponer una toma de conciencia y un cambio de actitud del administrador educativo, frente al cumplimiento de esta función sustantiva que le ha sido delegada a las universidades.

La ley 30 de 1992 procuró establecer dentro de sus objetivos el profundizar en la formación integral de todos los colombianos a fin de que las universidades formen profesionales con vocación de servicio social, que pudieran dar respuestas a las necesidades del país. Además, en el artículo 120 de la misma Ley, deja explicito que la extensión comprende entre otras cosas; la difusión de los conocimientos, el intercambio de experiencias y las actividades sociales con miras al desarrollo de las comunidades y la satisfacción de las necesidades de la sociedad.

Posteriormente, dentro de las políticas de calidad de la educación, el gobierno nacional viene legislado en torno a este concepto. La ley 1188 de 2008 fijó en su artículo 2; que dentro de las condiciones de calidad de los programas académicos se debería evidenciar una relación armónica con el entorno que proyecte la universidad a la sociedad.

Frente a dichas disposiciones es deber de las Universidades examinar de manera conjunta con las comunidades el desarrollo de estrategias que conlleven la potenciación de competencias en el estudiante, permitiendo su interacción adecuada con el entorno. En este sentido, la característica 28 de los Lineamientos para la Acreditación de programa académicos hace alusión a la extensión o proyección social, dentro del cual se prevé que desde la academia se enfrenten y minimicen los problemas y necesidades de las comunidades vulnerables, articulando en su plan de estudios los resultados de estas intervenciones.

Pudiera pensarse que estos lineamientos, claramente establecidos, en materia de extensión o proyección social han sido adoptados por las instituciones educativas, toda vez, que para formar integralmente y dar cumplimiento a su misión deben procurar el desarrollo de competencias en el estudiante, con el fin de que puedan interactuar con su entorno y contribuyan a la satisfacción de las necesidades de la población.

En esta dirección, la Conferencia Mundial sobre Educación Superior- 2009- (6), reitera que las universidades han de asumir el liderazgo social en la 
comprensión y abordaje de la problemática social mediante la potenciación del pensamiento crítico, ciudadanía activa y la interdisciplinariedad. Al respecto, Villa (7), viene afirmando que en Colombia se hace necesario la creación de una cultura académica alternativa que propicie la reorganización curricular potenciando la formación integral, para lo cual se hace necesario la flexibilización curricular y la pertinencia social, de tal forma que los procesos formativos que ofrecen en las universidades puedan articularse a los contextos sociales.

No obstante se evidencia, en la gran mayoría de las instituciones de educación superior, un divorcio entre la academia y la sociedad. No se han logrado establecer los canales de diálogo entre las instituciones con sus entornos que propendan por la identificación de proyectos comunes dinamizando el desarrollo integral de las regiones. En este escenario, las prácticas formativas que hacen parte de los planes de estudios de los diferentes programas académicos, se producen de forma desarticulada a las necesidades de la región, además, se evidencia poca o nula transferencia de saberes intersectoriales, lo que origina duplicidad en las acciones y mayores costes en la ejecución de los proyectos (8).

\section{La proyección social desde la perspectiva de la bacteriología}

No existe razón alguna para creer que las facultades y programas de bacteriología, no han debatido ni vivenciado el problema que le asiste a la educación superior en torno a ¿Cómo articular el proceso formativo a la proyección social? Si bien, existe una conciencia frente al hecho de la responsabilidad social de todos los programas académicos de la educación terciaria, es mucho el camino que falta por recorrer en los rediseńos curriculares. De tal forma, que éstos coadyuven a la formación de un profesional comprometido con el mejoramiento de la calidad de vida de las comunidades.

En esta dirección, cobran vigencia los planteamientos del Comité de Currículo del Programa de Microbiología y Bioanálisis de la Universidad de
Antioquia (9), cuando afirman que pese a que en los últimos ańos se ha evidenciado un interés por resignificar el carácter socio humanístico de los currículos de Bacteriología en el país, a fin de contribuir con la respuesta que la sociedad espera del sector de la salud, aún predomina la tendencia de formar profesionales idóneos en las áreas clínicas y la hematología, capaces de brindar una atención excelente en laboratorios públicos, hospitales y clínicas. El anterior supuesto se circunscribe en los argumentos de la Organización Mundial de Salud (10), en torno a que los esfuerzos que realizan las diferentes agencias del sector son inadecuados. Por tanto direccionan sus metas y objetivos hacia rumbos confusos, o lo hacen tarde, contribuyendo muy poco al desarrollo de la salud en términos de la equidad y la justicia social, como está pasando con la Academia.

Este duro cuestionamiento de la OMS, e invita a resignificar el papel que han de desempeñar las universidades en materia de extensión universitaria, dado que estas acciones no deben depender sólo de los esfuerzos y la sensibilidad social de un grupo de docentes y organizaciones civiles, dependen de la voluntad institucional en cumplimiento a la normatividad existente. Además, según lo anotan los seguidores del neo institucionalismo sociológico, urge recobrar la confianza de las comunidades, establecer redes de cooperación donde se puedan potenciar canales horizontales de diálogo, que faciliten visibilizar la voz de la sociedad civil con miras a influenciar los proyectos institucionales coadyuvando el establecimiento de nuevas formas de ver y abordar los problemas desde el entramado social que se gesta entre los diferentes actores que la conforman (11).

En este sentido, se podría decir que las personas viven y conviven en un mundo de instituciones cuyas relaciones determinan el desarrollo de una sociedad (12). Bajo estos argumentos, el Programa de Bacteriología de la Universidad de Córdoba- Colombia viene reflexionado en su actuar, desde hace algunos ańos, por una parte, para responder a las regulaciones gubernamentales en materia de calidad de 
la educación, por otra, porque somos conscientes que para cumplir con el perfil profesional que nos hemos trazado desde nuestra creación, el cual hace referencia a formar profesionales con especial fortaleza en el trabajo comunitario, se requiere entablar un diálogo permanente con la sociedad civil, para escuchar con atención sus demandas y actuar mancomunadamente en la definición de alternativas para superarlas.

Como no escuchar el clamor de una comunidad que refleja graves problemas de salud, especialmente de la población infantil, cuando las estadísticas del año 2006 que analizan el PNUD y el Observatorio del Caribe (13) en el marco de la evaluación de los Objetivos del Desarrollo del Milenio reflejan que las cifras de mortalidad infantil en el Caribe Colombiano son superiores al promedio nacional (15.5), ocupando el departamento de Córdoba el tercer lugar $(18,5)$, antecedido de los departamentos del Magdalena $(21,9)$ y La Guajira $(21,7)$. Situación que se aleja aún más, cuando se habla de mortalidad de la niñez (menores de cinco años), en la que Córdoba reporta una tasa de 22.3 por 1.000 nacidos vivos, frente a un promedio nacional ubicado en un 18.9. En lo que a enfermedades transmitidas por vectores se refiere, el Instituto Nacional de Salud Pública (14), reporta que en la semana epidemiológica 28 de 2012, Córdoba ocupa el tercer lugar de los departamentos con mayor proporción de casos de paludismo por departamento, antecedido por Antioquia y Chocó, constituyendo entre los tres departamentos el $72,9 \%$ de los casos notificados en el país.

En este aparte, serían muchos los aspectos que se podrían mencionar en materia de salud, educación, pobreza, desempleo y desigualdad social que afecta el bienestar y calidad de vida de los cordobeses, que a su vez sirvieron de fundamentos para la construcción del perfil profesional y ocupacional que nos trazamos desde el programa de Bacteriología de la Universidad de Córdoba. El cual necesariamente tuvo que trascender de los escenarios clínicos, administrativos y docentes al campo comunitario, porque nos negamos como profesionales de la salud a seguir tolerando que mueran por enfermedades prevenibles más niños, niñas y jóvenes. Nos negamos a que la academia continúe edificando murallas con estructuras rígidas que no se sensibilicen frente al dolor y la enfermedad; nos negamos a formar profesionales que sólo tengan en su haber la formación clínica, negándoles a ellos, a su vez, la oportunidad no sólo de comprender desde la teoría que el proceso de salud- enfermedad ha de abordarse desde una perspectiva holística en la que se tengan en cuenta todos los factores que determinan ese binomio, sino que lo vivencien e intervengan en sus prácticas comunitarias.

Es así, como se propone desde el programa de Bacteriología de la Universidad de Córdoba, la inserción real de la academia con la investigación y la extensión, específicamente en formar hombres y mujeres con sentido común y una alta sensibilidad social capaces de analizar las realidades sociales, y sobre esa base, orientar planes de acción para el desarrollo integral de las mismas. En consecuencia la función de extensión y proyección social del Programa de Bacteriología, se articula a la misión, visión y principios reguladores de la Universidad de Córdoba, en virtud de que genera de manera constante la reflexión de sus estudiantes frente a las necesidades de las poblaciones más vulnerables, mediante la utilización de todas las técnicas diagnósticas, el saber construido en sus aulas de clases y la generación permanente de nuevas estrategias para afrontar una sociedad cada vez más globalizada.

\section{Principios de la Proyección Social del Progra- ma de Bacteriología}

Concebir la academia sin encargo social es considerar que pueda darse el proceso de enseńanza aprendizaje sin estudiantes. El programa de Bacteriología ha estructurado su currículo partiendo de los principios básicos de fomentar el saber, saber hacer, saber ser y saber convivir, que en su conjunto, ilustran la aplicabilidad de los conceptos de 
relevancia y pertinencia en el marco de una educación de calidad (15). De allí se desprende la verdadera esencia del bacteriólogo que se ha formado con criterios para el trabajo comunitario y social, atendiendo los lineamientos de la UNESCO y de otros autores cuando afirman; que el referente de las universidades ha de ser las exigencias de la sociedad y no sólo el mercado $(16,17)$.

Por lo anterior, el programa de Bacteriología contempla como condicionante para ofrecer un programa de calidad, la proyección social. Es decir, que busca de forma permanente la materialización de su actuar en escenarios sociales y comunitarios, para ver reflejado los principios de calidad y equidad bases de la formación del futuro bacteriólogo.

Fundamentos del Programa de Extensión Universitaria: "Comunidades Educativas Sanas y Responsables".

Las familias cordobesas, en especial los niños, niñas, jóvenes tienen el derecho de crecer y formarse en un contexto saludable que les garantice el pleno desarrollo de su personalidad y la construcción del proyecto de vida familiar y comunitaria. Es precisamente el entorno, el lugar que debería ofrecer las oportunidades y protección que los miembros de la comunidad necesitan para alcanzar su desarrollo. Sin embargo, es evidente que los peligros asociados al agua, al aire contaminado y la falta de saneamiento básico aumentan el riesgo de enfermar de la población.

Por lo anterior, la estrategia que propone el Programa de Bacteriología de la Universidad de Córdoba, busca fomentar una cultura de promoción de la salud y prevención de las enfermedades que engarce el desarrollo de competencias del bacteriólogo en formación con la relación universidad-escuela- comunidades, potenciando el diálogo entre los diferentes agentes, para lo cual el currículo se reviste de elementos esenciales como son la interdisciplinariedad, corresponsabilidad, flexibilidad y la pertinencia social.
La importancia de esta conexión ampliamente desarrollada a lo largo de este texto, bebe de la interpretación que los docentes, estudiantes y egresados adscritos al programa, han hecho de los principios institucionales en relación con la responsabilidad social que le asiste con la región, partiendo de la concepción de que la proyección social ha de concebirse como una estrategia que aporta a la formación integral de los estudiantes, además de convertirse en una oportunidad que favorece la potenciación de las prácticas comunitarias.

Acorde con estos planteamientos, el Programa de Bacteriología formuló un proyecto académico de prácticas comunitarias enmarcado en dos de las cuatros áreas; la gestión educativa y social, que consolidan los recursos, acciones, metas, actores y procesos. En este orden, se puede resaltar que este proyecto se fundamentó en los principios rectores que ofrece la iniciativa propuesta por la Organización Mundial de la Salud y la Organización Panamericana de la Salud (18-21), quienes desde un enfoque multidisciplinario y una perspectiva integral conciben que la educación en salud ha de potenciar el desarrollo de competencias y capacidades en la que las personas puedan cuidar de sí mismo y de otros, minimizando los riesgos de los factores determinantes a los que se hayan expuestos. De la misma manera, aborda al sujeto en su medio natural como miembro activo de una familia, comunidad y de la sociedad en general.

La ruta metodológica abarcó, en primer lugar, el cambio de paradigma en torno al perfil profesional del bacteriólogo atendiendo al principio de que el pensamiento determina las acciones. Por lo tanto, era necesario dejar de pensar que el bacteriólogo sólo le pertenece a un laboratorio clínico desde el cual interpreta y le da sentido a los procesos asistenciales derivados del mismo; el profesional de la bacteriología está en la capacidad de interactuar en otros escenarios sociales. En segundo lugar, se dio espacio al diálogo curricular entre los contenidos organizados del plan de estudio y las realidades comunitarias, haciéndose necesario que los 
estudiantes, acompañados por docentes idóneos, recorrieran las comunidades para que a través de diagnósticos socio sanitarios determinaran las principales necesidades de salud de la población y, sobre esa base, plantear intervenciones comunitarias.

Esta integración de las expectativas y necesidades de las comunidades con la formación del bacteriólogo ha sido el elemento dinamizador que ha permitido un cambio institucional, reflejado en las ideologías de los profesores y administrativos frente al abordaje comunitario. Pero lo más importante, un cambio lento pero con grandes frutos en el bacteriólogo en formación, que ha venido comprendiendo la importancia de repensar y actuar con las comunidades.

La tarea que queda en la región de Córdoba- Colombia, es lograr la transformación de la concepción en torno al perfil del bacteriólogo al interior de las instituciones de salud. Reemplazando los viejos paradigmas frente al quehacer de la bacteriología con énfasis sólo en la clínica, por el un nuevo profesional de la salud capaz de diseñar, ejecutar y evaluar programas de promoción de la salud y prevención de las enfermedades, ganando espacios ocupacionales hasta hoy desconocidos, pese a que la Ley 841 de 2003, estipuló como campos de acción para estos profesionales; la promoción de la salud, la prevención, el diagnóstico, pronóstico y tratamiento de la enfermedad.

\section{Componentes del programa "Comunidades Sanas y Responsables"}

Acorde con la naturaleza educativa y social del programa se definieron los componentes salud, educación y de gestión institucional que interrelacionados pretenden ofrecer una nueva mirada al tránsito de concepción ocupacional de la profesión de bacteriología. En el componente salud se definieron líneas de acción que involucran el diagnóstico sanitario de las comunidades vulnerables. Teniendo en cuenta la interrelación del agente causal que puede ser según el caso; bacteria, virus, hongos o parásitos con el medio ambiente que potencia o minimiza la proliferación de los microorganismos y el huésped susceptible, que se asimila para efectos de estas prácticas a los seres humanos. Además, se articula con las prácticas de laboratorios mediante las cuales se pueden establecer los diagnósticos clínicos, que sirven de soporte para el análisis de la situación de salud de la comunidad atendida.

En el componente educativo confluyen diversas áreas del conocimiento, por una parte, los estudiantes ponen en práctica las competencias en el campo de la investigación, diseñando instrumentos y aplicando técnicas que permiten la recolección, organización y análisis de la información requerida por el diagnóstico sanitario. Por otra parte, las áreas clínicas alimentan esta visión brindando elementos teórico-prácticos en la identificación de factores determinantes de las enfermedades, prevención y tratamiento de las mimas. En esta dirección, es vital la reorientación de la asignatura de Trabajo Comunitario, la cual debe, entre otras, fortalecer las habilidades y destrezas en la planeación, organización y evaluación de estrategias comunitaria, así como también, se hace necesario que se ofrezcan elementos metodológicos para el diseño de materiales educativos, actividades y didácticas del aprendizaje acordes con la temática abordada.

Este componente también vela porque el estudiante de Bacteriología fortalezca sus competencia en el campo del trabajo comunitario, siendo capaces de desarrollar procesos formativos desde la óptica de la acción participación, en la que conjuntamente con las comunidades intervenidas identifique los mecanismos y estrategias necesarias para minimizar los problemas de salud y elevar la calidad de vida de las personas, familias y comunidades.

El componente de la gestión institucional, se potencia en la medida en que se establecen alianzas entre los diferentes actores de la sociedad civil con la academia desarrollando iniciativas en el campo de la educación salud, partiendo siempre de la formación investigativa, desarrollando competencias en el campo del trabajo social y comunitario, y siendo capaces de generar una lectura crítica y reflexiva de la 
realidad que retornará a la Universidad, con el propósito de reorientar las prácticas, estableciéndose fuertes canales y un diálogo emancipador que coadyuve al desarrollo social y sostenible de las regiones.

\section{Conclusiones}

Existe un creciente interés de resignificar el papel y responsabilidad de las universidades en la construcción de una sociedad justa, ecuánime y solidaria que promueva el desarrollo integral de todas las personas, para lo cual se acusa el protagonismos de los programas académicos como responsables directos de la formación de profesionales, con capacidades de articular la docencia, extensión e investigación, aportando reflexiones y análisis pertinentes para interpretar las necesidades sociales y proponer de forma crítica alternativas de solución a las mismas.

En este marco, surge el concepto de formación integral, como eje articulador de toda la intencionalidad educativa, que exige potenciar competencias en los estudiantes que equiparen el saber, saber ser, saber hacer y saber convivir como mecanismos que permitan responder a las demandas del contexto.

Finalmente, se han de potenciar todos los espacios curriculares que sitúan a los bacteriólogos en formación, en un mismo entorno con los problemas sociales, agentes educativos y conocimientos, pudiendo visibilizar la articulación eminente entre la academia, investigación y la proyección social.

\section{Referencias}

1. Berger P, Luckmann T. La construcción social de la realidad. Decimoséptima Reimpresión. Argentina: Amorrortu Editores; 2001. http://www.escriturayverdad.cl/FILOSOFIA/5.pdf.

2. Harvey C, Marrett C. Educación para el desarrollo humano y social en el Caribe. En: Global University Network for Innovation, editor. La educación superior en el mundo 2008: Nuevos retos y roles emergentes para el desarrollo humano y social. Argentina: Editorial Mundiprensa; 2008: 283-304.

3. República de Argentina. Universidad Nacional de Córdoba. Manifiesto Liminar; 1918- [fecha de acceso 07 de mayo de 2013]. Disponible en: http://www.unc.edu.ar/institucional/ historia/reforma/manifiesto.

4. North, D. Institutions, Institutional Change and Economic Performance. New York: Cambridge University Press. 1990.

5. Del Castillo Alemán, G. Una propuesta analítica para el estudio del cambio en las instituciones de educación superior.
Perfiles Educativos [Revista en internet]. 2006 enero- marzo. [acceso el 06 de mayo de 2013]; vol. XXVIII (111). Disponible en: http://www.redalyc.org/articulo.oa?id=13211103

6. Organización de las Naciones Unidas para la educación, la ciencia y la cultura- UNESCO-. Conferencia mundial sobre la educación superior- 2009: La nueva dinámica de la educación superior y la investigación para el campo social y el desarrollo. París: UNESCO; 2009.

7. Díaz Villa, M. Flexibilidad y educación superior en Colombia. 2 ed. Bogotá: ICFES; 2002.

8. Organización para la Cooperación y el Desarrollo Económico (OCDE) y Banco Mundial. La educación superior en Colombia 2012. Serie Evaluaciones de Políticas Nacionales de Evaluación; 2012

9. Universidad de Antioquia. Escuela de Bacteriología y Laboratorio Clínico. Comité de Currículo: Programa de Bacteriología y Bioanálisis. Medellín: La Escuela; 2003

10. Organización Mundial de la Salud- OMS-. Informe sobre la salud primaria en salud 2008. La atención primaria de salud más necesaria que nunca. Washington: OMS, 2008

11. Engelken-Jorge, M. ¿La sociedad civil como agente democratizador? Una aproximación desde la teoría política. Nómadas. Revista Crítica de Ciencias Sociales y Jurídicas [revista en Internet]. 2011 [acceso 02 de mayo de 2013]; 32(4). Disponible en: http://www.ucm.es/info/nomadas/32/marcosengelken.pdf

12. Rivas Leone, JA. El neoinstitucionalismo y la revalorización de las instituciones. Reflexión política [revista en internet]. 2003 junio [acceso 03 de mayo de 2013]; 9. Disponible en: http://biblma.pcp.mx/archivos/Neoinistitucionalismo\%20 y\%20revalorizacion.pdf

13. Programa de las Naciones Unidas para el DesarrolloPNUD-, Observatorio del Caribe Colombiano. El caribe colombiano frente a los Objetivos de Desarrollo del Milenio. Colombia: PNUD

14. Instituto Nacional de Salud. Boletín Epidemiológico Semanal. Semana Epidemiológica Número 28 de 2012 (8 al 14 de julio de 2012). Bogotá: Instituto Nacional de Salud; 2012.

15. Comisión Económica para América Latina y el Caribe (CEPAL) y Organización de los Estados Iberoamericanos para la Educación, la Ciencia y la Cultura (OEI). Metas Educativas 2021. Estudio de Costos. Santiago de Chile: Comisión de Desarrollo Social; 2009.

16. Organización de las Naciones Unidas para la Educación, la Ciencia y la Cultura. Declaración Mundial sobre la Educación Superior en el Siglo XXI: Visión y Acción y Marco de acción prioritaria para el cambio y el desarrollo de la educación superior. París: Conferencia Mundial sobre la Educación Superior; 1998.

17. Tunnermann Bernheim, C. La educación superior frente a los desafíos contemporáneos. Nicaragua. Universidad Centroamericana; 2011.

18. Organización Mundial de la Salud, Organización Panamericana de la Salud. Escuelas Promotoras de Salud: Fortalecimiento de la Iniciativa Regional, Serie Promoción de la Salud No. 14. Washington; 2003.

19. Restrepo, H. y Málaga, H. Promoción de la Salud: cómo construir una vida saludable. Colombia: Panamericana; 2001. 